\title{
DIFFERENTIAL DIAGNOSTICS OF INHERITED METABOLIC DISORDERS IN NEWBORNS
}

DOI: 10.36740/WLek202006125

\author{
Tetiana K. Znamenska', Olga V. Vorobiova' ${ }^{1}$, Tetiana V. Holota', Vera V. Kryvosheieva² ${ }^{2}$ Valeriy I. Pokhylko ${ }^{3}$ \\ 'SI"INSTITUTE OF PEDIATRICS, OBSTETRICS AND GYNECOLOGY NAMED AFTER ACADEMICIAN O. M. LUKYANOVA OF THE NAMS OF UKRAINE”, KYIV, UKRAINE \\ ²DONETSK NATIONAL MEDICAL UNIVERSITY, LYMAN, UKRAINE \\ 3UKRAINIAN MEDICAL STOMATOLOGICAL ACADEMY, POLTAVA, UKRAINE
}

\begin{abstract}
The aim: To compose an applicable diagnostic checklist for neonatologists, pediatricians, and general practitioners who refer newborns with certain inherited metabolic diseases (IMDs) suspicion to confirmatory testing laboratories.

Materials and methods: Analyzed international and generally, known national clinical guides and recommendations devoted to IMDs diagnostics, treatment and follow up. Results: Considering integral character of the diagnostic work-up of inborn errors of metabolism, authors of this article composed an applicable checklist that comprises set of data necessary for interpretation the positive results of expanded newborn screening and making decision of appropriate biochemical and molecular tests are required for confirmatory follow-up testing to establish the diagnosis and prescribe pathogenetic therapy.

Conclusions: Properly filled checklist allow metabolic professionals to select appropriate confirmatory tests and interpret results obtained. Early IMDs diagnosis and prompt treatment initiation are crucial for positive outcomes and proved to be an effective tool to decrease levels of child disability and infant mortality.
\end{abstract}

KEY WORDS: newborns, differential diagnosis of inherited metabolic diseases (IMDs), expanded newborn screening, confirmatory testing

Wiad Lek. 2020;73(6):1211-1216

\section{INTRODUCTION}

Inherited metabolic disorders (IMDs) are orphan diseases which result from the genetic defects of enzymes involved in amino acids, carbohydrates, organic and fatty acids metabolism. Clinical signs of IMDs are nonspecific and don't differ from those for majority of common pediatric pathologies. The latter presents certain difficulties for doctors in diagnosis establishing, causes errors and finally takes too much time to avoid severe consequences like irreversible damage of the brain and internal organs due to late start of pathogenetic therapy. About $70 \%$ of IMDs have an acute manifestation, but in neonatal period such clinical states like sepsis, hypoxic ischemic encephalopathy, heart failure, and intestinal obstruction can disguise the presence of metabolic disorder causing delay in diagnostics. In severe cases delay in diagnostics may lead to the development of metabolic decompensation state, rapidly progressive multiple organ failure, mental retardation or death of a neonate [1].

Early detection of IMDs by means of expanded newborn screening and further confirmatory testing for newborns with suspected metabolic disorder having positive screening results or for neonate demonstrating clinical signs allow physicians to start specific pathogenic therapy as early as possible. Early and diagnostics of IMDs requires proper description of pregnancy and childbirth history, notes of neonatal period flow, and the results of key laboratory and clinical examinations of a child since his(her) birth. All the data has to be recorded and sent to a specialist in IMDs laboratory diagnostics and to endocrinologists. Interpretation of biochemical findings, correctness of differential diagnostics, and final diagnosis establishing in certain extent depends on the volume of anamnestic data, and the results of clinical and laboratory examinations. Diagnostic errors lead to the delay in pathogenic treatment initiation, and ultimately - to pessimistic medical prognosis of normal development of newborn [2].

\section{THE AIM}

To compose an applicable diagnostic checklist for neonatologists, pediatricians, and general practitioners who refer newborns with certain IMD suspicion to confirmatory testing laboratories.

\section{MATERIALS AND METHODS}

Analyzed international and generally, known national clinical guides and recommendations devoted to IMDs diagnostics, treatment and follow up. We focused at the diagnostic algorithms of more dangerous and frequent diseases that were included in the internationally recognized core panel of expanded newborn screening. Special attention was paid to IMDs with prompt progression to metabolic crisis states. 


\section{RESULTS AND DISCUSSION}

Considering integral character of the diagnostic work-up of inborn errors of metabolism, authors of this article composed an applicable checklist that comprises set of data necessary for interpretation the positive results of expanded newborn screening and making decision of appropriate biochemical and molecular tests are required for confirmatory follow-up testing to establish the diagnosis and prescribe pathogenetic therapy. The checklist form should be filled by a physician and sent to the laboratory along with the samples of biomaterial to perform confirmatory tests.

Objective information in this checklist is used as for planning further confirmatory diagnostics activity, as for assessing results of biochemical, instrumental and genetic investigations to confirm or exclude mutation defect of certain enzyme in specific metabolic pathway, and to improve differential IMDs diagnostics of metabolic disorders suspected according to the results of the expanded newborn screening. Checklist can be seen in Annex.

Inherited metabolic disorders can be grouped into several categoris: (I) classic IMD - disorders of intermediary metabolism, (II) disorders of biosynthesis and breakdown of complex molecules, and (III) disorders of neurotransmitter metabolism. Performing differential diagnostics of IMDs it is necessary to consider family history, manifestation and clinical features (such as organomegaly, cardiomyopathy, haematological abnormalities, developmental defects, and signs of dysmorphogenesis). These data are key important for proper understanding and interpretation results of instrumental examinations and clinical laboratory data (such as hypoglycemia, ketosis, hyperammonemia, persistent metabolic lactate acidosis, respiratory alkalosis, cholestatic syndrome, and hyperbilirubinemia which is not caused by hemolytic disease of newborns) $[3,4]$.

Some IMDs can cause problems during pregnancy and labor (nonketotichyperglycinemia, peroxisomal defects, disorders of cholesterol biosynthesis, lysosomal storage diseases). For instance, low level of maternal serum estriol in case of steroid sulfatase deficiency or multiple sulfatase deficiency, due to defects of certain enzyme from sulfatases family being element of cholesterol biosynthesis pathway; reduced fetal movements in case of multiple affected organs (Smith-Lemli-Opitz syndrome, glycogen storage disease type IV, some lysosomal and peroxisomal disorders); HELLP syndrome, acute fatty liver of pregnancy (long-chain acyl-CoA dehydrogenase deficiency). Steroid sulfatase deficiency can cause prolonged labor as a result of decrease in the placental estrogen production. During IMDs diagnostics it is necessary to consider perinatal loss (miscarriage, ectopic pregnancy, stillbirth, neonatal death, sudden death syndrome cases), as well as consanguineous marriage, and siblings' state of health. Intrauterine growth retardation, dysmorphia, Banti syndrome, and nonimmune fetal hydrops can also be caused by metabolic disorders. Signs of dysmorphogenesis are typical for peroxisomal disorders (large fontanelles, high forehead, hypoplastic supraorbital ridges, epicanthal folds, hypoplasia of the nasal bone in case of Zellweger syndrome), Pyruvate De- hydrogenase deficiency (epicanthal folds, nose anomalies), mitochondrial disorders (epicanthal folds, hypoplasia of the nasal bone), glutaricaciduria type II (macrocephaly, high forehead, hypoplasia of the nasal bone, ear anomalies, hypospadias), mevalonic aciduria (large fontanelles, high forehead, hypertelorism, epicanthal folds, low-set ears) [5].

It's necessary to remember that the absence of the burden family history does not exclude the risk of birth of a child with inherited metabolic disorder, since the majority of these disorders demonstrate the autosomal recessive type of inheritance [6].

Usually, it's impossible to diagnose IMDs during routine medical examination of newborns due to the absence of specific clinical symptoms. Most diseases of organic acidemias group, as well as urea cycle defects and amino acid metabolism disorders can manifest with acute metabolic emergencies and acute metabolic encephalopathy resulting in significant morbidity. Characteristic symptoms of this state are developed as a consequence of toxic metabolites accumulation in the blood and tissues due to "metabolic block", and its damaging action upon the central nervous system and internal organs. Clinical courses of majority IMDs are characterized by initial asymptomatic period, so called "light interval" can last from a few hours to a few months and even years. Most frequent provocative factors of emergencies in suspected inborn errors of metabolism are states characterized by catabolic processes predominance (such as infection, episodes of prolonged starvation, dehydration, surgical intervention, trauma, vaccination) or excessive consumption of proteins or carbohydrates. Clinical picture is characterized by nonspecific signs or sudden deterioration of a newborn's health state. A neonate can demonstrate symptoms of enteral feeding intolerance, vomiting, respiratory impairments, apnea, lethargy, somnolence, hypotonia (poor muscle tone, commonly known as floppy baby syndrome), and seizures [7]. Vomiting, being a consequence of intoxication, represents one of the most common signs of IMDs in infants, but early vomiting manifestation soon after birth is considered a sign of severe disease course.

Clinical suspicion of IMDs is paramount. To keep up high index of IMDs awareness in newborns, physicians should start analysis of causes of any critical newborn state from exclusion inherited metabolic disorders. Particularly, in cases of severe neonatal encephalopathy, cardiomyopathy of unclear genesis, persistent hypoglycemia, elevated liver enzymes with coagulopathy, ketoacidosis, electrolyte balance disorder, and metabolic acidosis with high anion gap. Anion gap (AG) is the simple blood test indicating occurence of decompensated shift in acid-base balance in the body. AG is calculated calculated by subtraction sodium cations content from the sum of chlorides and bicarbonates anion content $\left(\mathrm{AG}=\left(\mathrm{Na}^{+}-\left(\mathrm{Cl}^{-}+\mathrm{HCO}_{3}^{-}\right)\right)\right.$. A normal value of the anion gap is $3-12 \mathrm{mEq} / \mathrm{L}$. Blood $\mathrm{pH}$ less than 7.40 with low bicarbonates upon AG calculation allows to confirm metabolic acidosis. AG serves a key indicator to determine the causes of metabolic acidosis in neonates. High anion gap $(>15 \mathrm{mEq} / \mathrm{L})$ is a sign of decompensated 
Table I. Early neurosonography brain changes

\begin{tabular}{|c|c|c|}
\hline Metabolic disease & Specific brain changes & Diagnostic methods \\
\hline Maple syrup urine disease & $\begin{array}{c}\text { Brain swelling, echogenicity changes, structural white and grey } \\
\text { matter changes }\end{array}$ & Neurosonography, MRI \\
\hline $\begin{array}{l}\text { Oxidative phosphorylation } \\
\text { disorders }\end{array}$ & $\begin{array}{l}\text { Ventricular dilatation, subependymalgerminolysis, anomalous white } \\
\text { matter }\end{array}$ & Neurosonography, MRI \\
\hline Peroxisomal disorders & $\begin{array}{l}\text { Ventricular hypertrophy, lenticulostriatevasculopathy, cortex tissue } \\
\text { anomalous structure }\end{array}$ & Neurosonography, MRI \\
\hline Organic acidemias & Increased echogenicity of the periventricular white matter & Neurosonography \\
\hline $\begin{array}{l}\text { Amino acid metabolism } \\
\text { disorders, urea cycle } \\
\text { disorders }\end{array}$ & $\begin{array}{l}\text { Cortex tissue anomalous structure, anomalous white matter, corpus } \\
\text { callosum hypoplasia }\end{array}$ & Neurosonography, MRI \\
\hline Sulfite oxidase deficiency & $\begin{array}{l}\text { Cystic formation of the white matter, possible corpus callosum } \\
\text { hypoplasia and ventriculomegaly. Basal ganglia can imitate certain } \\
\text { patterns of the course of hypoxic ischemic damages }\end{array}$ & Neurosonography, MRI \\
\hline $\begin{array}{l}\text { Molybdenum cofactor } \\
\text { deficiency }\end{array}$ & $\begin{array}{l}\text { Early signs of a diffuse increase in echogenicity, later - brain tissue } \\
\text { hyperechogenicity and basal ganglia calcification, cysts in white } \\
\text { matter, later - cerebral atrophy }\end{array}$ & Neurosonography, MRI \\
\hline Zellweger Syndrome & $\begin{array}{l}\text { Subependymal cysts, ventricular hypertrophy, } \\
\text { lenticulostriatevasculopathy, cerebral sulci and gyri defects }\end{array}$ & Neurosonography, MRI \\
\hline Nonketotichyperglycinemia & Corpus callosum hypoplasia & MRI \\
\hline
\end{tabular}

state of acid-base balance due to accumulation of organic acids in blood, which is a characteristic feature of organic acidurias. It is important to note that the AG decreases by $2.5 \mathrm{mEq}$ for every $1 \mathrm{~g} / \mathrm{dL}$ decrease in serum albumin [8].

It often happens that inherited metabolic disorders are misdiagnosed as neonatal sepsis, hypoxic ischemic encephalopathy, gastrointestinal bleeding, or asphyxia.

Sepsis proved to be the initial consideration in a newborn with lethargy, poor feeding, respiratory impairments, and recurrent vomiting. But inborn errors of metabolism should always be considered and excluded, particularly in a full-term infant demonstrating prompt progression of clinical symptoms after initial well-being period. Signs of systemic inflammatory response (clinical picture of gram-negative sepsis) can occur in case of galactosemia, organic acidemias, urea cycle disorders, and congenital hyperplasia of adrenal glands. Rather often galactosemia in newborns is mistakenly diagnosed as sepsis caused by e. coli. Generally, absence of positive dynamics in neonate clinical state on the background of symptomatic therapy performance should be considered as a possible manifestation of IMDs [9].

Seizures presents another clinical signs being characteristic of many inherited metabolic disorders. Seizures can occur during the prenatal period (fetal seizures, clonic convulsions), being refractory to common antiepileptic treatment. Convulsion syndrome is typical for amino acid metabolism and urea cycle disorders, organic acidemias, gangliosidosis, pyruvate metabolism disorders, peroxisomal disorders, mitochondrial disorders, biotinidase deficiency, glycine encephalopathy, molybdenum cofactor deficiency, sulfite oxidase deficiency, disorders of creatine, purine and pyrimidine metabolism. These pathologies are accompanied by progressive deterioration of neonate clinical status (noted in all organs and systems of the body), including electroencephalographic, and neurosonographic indicators as well [10].

Another integral part of the diagnostic work-up of metabolic disorders are the results of instrumental investigations and brain imaging. The cranial ultrasonography due to the bedside availability allows brain imaging in symptomatic neonates shortly after birth to detect early signs of the brain abnormalities. Early structural brain abnormalities associated with certain metabolic disorders are summarized in Table I.

As far as the signs and symptoms of IMDs are nonspecific and often overlap extensively with more common disorders, clinical laboratory diagnostics plays a key role in the diagnostic work-up of these diseases. Particularly at early (preclinical) stage when the elevated blood concentration of marker (or even pathognomonic) products of impaired metabolic pathway could be reliably detected before an IMD debut. For these purposes complicated analytical methods such as: tandem-mass-spectrometry, gas chromatography-mass-spectrometry etc. are used. These extremely sensitive multiplex methods allow determining concentration of several dozens or hundreds substances in single blood or urine sample. For correct interpretation of this data, specialists in metabolic disorders also need results of routine laboratory analyses (blood gases, electrolytes, anion gap, levels of glucose, lactate, and ammonium in the blood). Considering progredient and rapidly progressive course being characteristic of certain IMDs group, pathogenetic therapy is recommended to start right away 
after revealing gross deviation of the results of expanded newborn screening in dried blood spots from referent values, even in the absence of clinical manifestations of the disease and incompleted confirmatory investigations that are stipulated by the diagnostic work-up [11].

In fact, differential diagnostics between inherited metabolic diseases and severe somatic pathologies in newborns being serious challenge to physicians due to: nonspecific symptoms and signs, progredient prompt progression, and severe outcomes in case of absence or late start of pathogenetic therapy [12]. To help physicians to systematize diagnostically relevant information and arrange in a schematic form the complex of anamnestic data, clinical manifestations, results of routine clinical laboratory tests, and findings of instrumental examinations we propose the form of above-mentioned checklist (Annex). It's believed that routine usage of this form in everyday practice allows to speed up the differential diagnostics of IMDs by shortening the search of potentially suspected diseases. In our experience, this form proved to be very helpful in communication between metabolic specialists and family medicine physician in remote areas upon receipt of the positive results of the expanded newborn screening and impossibility to transfer a neonate to regional or central perinatal facilities.

\section{CONCLUSIONS}

Properly filled checklist allow metabolic professionals to select appropriate confirmatory tests and interpret results obtained. Early IMDs diagnosis and prompt treatment initiation are crucial for positive outcomes and proved to be an effective tool to decrease levels of child disability and infant mortality.

\section{REFERENCES}

1. Engel P.A., et al. Physician and patient perceptions regarding physician training in rare diseases: the need for stronger educational initiatives for physicians. Journal of Rare Disorders 2013;1, Issue 2. Online: http://www.journalofraredisorders.com/pub/lssuePDFs/Engel.pdf Lastaccessed January 2015.

2. Mohamed S. Recognition and diagnostic approach to acute metabolic disorders in the neonatal period. Sudan J Paediatr. 2011;11(1):20-8

3. Mavropulo T.K. Vrodzheni porushennya metabolizmu u novonarodzhenykh - neobkhidnist' skryninhu [Congenital metabolic disorders in newborns - the need for screening]. Neonatology, surgery and perinatal medicine. 2014;4(4):97-102. (In Ukrainian).

4. Joe T. R. Clarke, A Clinical Guide to Inherited Metabolic Diseases, 2002; 134-136.

5. Ozben T. Expanded newborn screening and confirmatory follow-up testing for in born errors of metabolism detected by tandem mass spectrometry. Clin Chem Lab Med 2013;51:157-76
6. Mak C.M., Lee H.C., Chan A.Y., Lam C.W. In born errors of metabolism and expanded newborn screening: review and update. Crit Rev Clin Lab Sci. 2013;50(6):142-62. doi: 10.3109/10408363.2013.847896.

7. Americal College of Medical Genetics Newborn Screening Expert Group Newborn screening: toward a uniform screening panel and systemexecutive summary. Pediatrics 2006; 117: S296-307.

8. Stevenson D.K, Cohen R.S., Sunshine P. Neonatology: Clinical Practice and Procedures. New York: McGraw-Hill, 2015; p. 649-64.

9. Saudubray J.M., Garcia-Cazorla A. In born Errors of Metabolism Overview: Pathophysiology, Manifestations, Evaluation, and Management. Pediatr Clin North Am 2018; 65: 179-208.

10. Gilbert-Barness E., Farrell P.M. Approach to diagnosis of metabolic diseases. Transl Sci Rare Dis 2016; 1: 3-22.

11. Nenad Blau, Marinu sDuran, K. Michael Gibson, Carlo Dionisi-Vici (Eds.) Physician's Guide to the Diagnosis, Treatment, and Follow-Up of Inherited Metabolic Diseases, 2014; p. 867.

12. N. Blau M. Duran, M. E. Blaskovics, K. M. Gibson (Eds.) Physician's Guide to the Laboratory Diagnosis of Metabolic Diseases, 2003 : 309-334.

"To develop and implement a system of medical and psychological support for newborns at risk of chronic morbidity, disability and developmental delay»; $0117 U 004538$.

\section{Funding:}

Sources of financing - State budget funds.

\section{ORCID and contributorship:}

Tetiana K. Znamenska - 0000-0001-5402-1622 A,E

Olga V. Vorobiova - 0000-0001-5199-0217 B,E

Tetiana V. Holota - 0000-0001-6816-7438 B,D

Vera V. Kryvosheieva - 0000-0001-6252-8220 ${ }^{B, D}$

Valeriy I. Pokhylko - 0000-0002-1848-0490 A,F

\section{Conflict of interest:}

The Authors declare no conflict of interest.

\section{CORRESPONDING AUTHOR Olga V.Vorobiova}

SI “Institute of Pediatrics, Obstetrics and Gynecology named after academician 0. M. Lukyanova of the NAMS of Ukraine" Platona Mayborody, 8, 04050, Kyiv, Ukraine

tel: +380991221944

e-mail:dr.vorobiova@ukr.net

Received: 28.02.2020

Accepted:30.04.2020 
Annex. CHECKLIST.REFERRAL TO THE DETAILED LABORATORY DIAGNOSTICS

\begin{tabular}{|c|c|c|}
\hline \multicolumn{3}{|c|}{ Patient (Child) Full Name_ } \\
\hline Patient Age & Patient DOB & Date_ \\
\hline \multicolumn{3}{|c|}{ Mother Full (Maiden) Name: } \\
\hline \multicolumn{3}{|c|}{ Patient Address: } \\
\hline \multicolumn{3}{|c|}{ Pre-diagnosis: } \\
\hline \multicolumn{3}{|c|}{ Referring Physician } \\
\hline \multicolumn{3}{|c|}{$\begin{array}{l}\text { HISTORY:Family (parents' state of health/age, cases of inherited diseases among close } \\
\text { relatives, information about previous pregnancies, resulted in, cases of children's deat } \\
\text { hs): }\end{array}$} \\
\hline \multicolumn{3}{|c|}{ Antenatal (which pregnancy/development of pregnancy): } \\
\hline Intranatal (course c & & Gestation period \\
\hline \multicolumn{3}{|c|}{ Causes of preterm labor } \\
\hline \multicolumn{2}{|l|}{ Birth weight } & Apgar score \\
\hline \multicolumn{3}{|c|}{ Newborn baby: no symptoms } \\
\hline \multicolumn{3}{|c|}{ Patient general condition (at the time of filling in the form) } \\
\hline \multicolumn{3}{|c|}{ Treatment (mention infusion therapy and hemotransfusion) } \\
\hline \multicolumn{3}{|c|}{ Type of feeding: } \\
\hline \multicolumn{3}{|c|}{ DIAGNOSTICS: } \\
\hline \multicolumn{3}{|c|}{ Primary research results: } \\
\hline
\end{tabular}

\section{MATERIAL ATTACHED TO MEDICAL RECORD:}

- dried blood spots on paper;

- urine;

- plasma/serum;

- $\quad$ EDTA test tube with blood (for molecular testing)

Attention! In case of infusion therapy in a child it's recommended to suspend intravenous infusions 3 hours before biomaterial sampling for analysis. CLINICAL SYMPTOMS

\begin{tabular}{|c|c|c|c|c|c|}
\hline Muscle tone disorders & Yes/No & Note & Diarrhea & Yes/No & Note \\
\hline Coma & Yes/No & & Hepatomegaly & Yes/No \\
\hline Tremor & Yes/No & & Cardiomegaly & Yes/No & Yes/No \\
\hline Convulsion & Yes/No & & Cardiomyopathy & Yes/No & Yes/No \\
\hline $\begin{array}{c}\text { Vomiting/ spitting up } \\
\text { Dynamics of weight }\end{array}$ & $\begin{array}{c}\text { Pesitive } \\
\text { Negative } \\
\text { Absent }\end{array}$ & & $\begin{array}{c}\text { Swelling/pastosity (of } \\
\text { face, body, limbs) }\end{array}$ & \\
\hline $\begin{array}{c}\text { Other symptoms } \\
\text { Comments }\end{array}$ & & & & & \\
\hline
\end{tabular}

\section{LABORATORY PARAMETERS \\ COMPLETE BLOOD COUNT}

\begin{tabular}{|c|l|l|l|}
\hline Parameter/Date & & & \\
\hline Red blood cells (RBC) & & & \\
\hline Hemoglobin (Hb) & & & \\
\hline Hematocrit (Hct) & & & \\
\hline $\begin{array}{c}\text { Thrombocyte/Platelet count } \\
\text { (PIt) }\end{array}$ & & & \\
\hline White Blood Cell Count (WBC) & & & \\
\hline
\end{tabular}


Tetiana K. Znamenska et al.

\begin{tabular}{|c|l|l|l|}
\hline Eosinophils/basophils & & & \\
\hline Metamyelocytes/myelocytes & & & \\
\hline Bands & & & \\
\hline Segmented neutrophils & & & \\
\hline Lymphocytes & & & \\
\hline Monocytes & & & \\
\hline
\end{tabular}

\section{BIOCHEMISTRY}

\begin{tabular}{|c|l|l|l|}
\hline Parameter/Date & & & \\
\hline Ammonium & & & \\
\hline Creatine phosphokinase & & & \\
\hline Lactate dehydrogenase & & & \\
\hline Glucose & & & \\
\hline Total bilirubin & & & \\
\hline Direct bilirubin & & & \\
\hline ALT & & & \\
\hline AST & & & \\
\hline Protein & & & \\
\hline Alkaline phosphatase & & & \\
\hline GGT & & & \\
\hline Creatinine & & & \\
\hline Urea & & & \\
\hline
\end{tabular}

\section{ACID-BASE STATUS}

\begin{tabular}{|c|l|l|l|}
\hline Parameter/Date & & & \\
\hline $\mathrm{pH}$ & & & \\
\hline $\mathrm{pCO} 2$ & & & \\
\hline $\mathrm{pO} 2$ & & & \\
\hline $\mathrm{HCO}-$ & & & \\
\hline $\mathrm{BE}$ & & & \\
\hline Aniongap Na+-(Cl- + $\mathrm{HCO}-)$ & & & \\
\hline
\end{tabular}

\section{ELECTROLYTES}

\begin{tabular}{|c|l|l|l|}
\hline Indicator/Date & & & \\
\hline $\mathrm{K}+$ & & & \\
\hline $\mathrm{Na}+$ & & & \\
\hline $\mathrm{Ca}++$ & & & \\
\hline $\mathrm{Cl}^{-}$ & & & \\
\hline $\mathrm{P}^{3+}$ & & & \\
\hline
\end{tabular}

\section{URINALYSIS}

\begin{tabular}{|c|c|c|c|}
\hline Parameter & Results & Parameter & Results \\
\hline $\mathrm{pH}$ & & Bilirubin & \\
\hline Color/odor & & RBC & \\
\hline Relative density & WBC & \\
\hline Protein & & Bacteria & \\
\hline Glucose & & Epithelium (squamous) & \\
\hline Ketone bodies & & Cylinders (hyaline, granular) & \\
\hline
\end{tabular}

Date:

Doctor's Signature: 